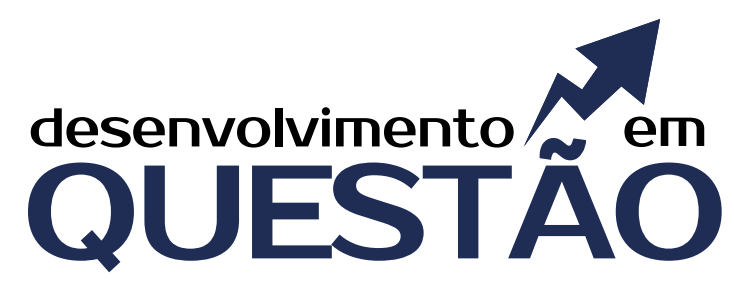

\title{
Determinantes do Desempenho dos Participantes da Prova do Enem: Evidências para o Rio Grande do Sul
}

http://dx.doi.org/10.21527/2237-6453.2020.53.352-368

Recebido em: 18/4/2020

Aceito em 18/8/2020

\author{
Ronaldo Torres, ${ }^{1}$ Mateus Machado de Pereira, ${ }^{2}$ \\ Reisoli Bender Filho, ${ }^{3}$ Fernanda Cigainski Lisbinski ${ }^{4}$
}

\begin{abstract}
RESUMO
O estudo da diferença do desempenho escolar entre as escolas de natureza pública e privada mostra-se importante às políticas públicas, principalmente as que relacionam políticas sociais para o ingresso no Ensino Superior. Desta forma, o presente trabalho propõe-se a averiguar a ocorrência de diferenças entre os ensinos público e privado, no Estado do Rio Grande do Sul, a partir do desempenho dos alunos no Exame Nacional do Ensino Médio (Enem), no ano de 2017. Para isso aplicou-se a modelagem de regressão quantílica decomposta em quartis à distribuição condicional da proficiência. Os resultados mostraram-se favoráveis ao desempenho dos alunos de escolas de natureza privada, de forma crescente, para os quartis, e que possuem melhores condições socioeconômicas familiares, como renda e mãe com formação no Ensino Superior. São evidências que demandam políticas públicas de equalização de possibilidades ao acesso ao Ensino Superior como forma de minimizar as crescentes desigualdades educacionais.
\end{abstract}

Palavras-chave: Desempenho escolar. Enem. Regressão quantílica.

PERFORMANCE DETERMINANTS OF ENEM TEST PARTICIPANTS: EVIDENCE FOR THE RIO GRANDE DO SUL

\section{ABSTRACT}

The study of the difference in school performance between public and private schools is important for public policies, especially those that relate social policies for entering higher education. In this way, the article aims to investigate the occurrence of differences between public and private education, in the state of Rio Grande do Sul, based on the performance of students in the National High School Exam (NHSE), in 2017. For that it was applied quantile regression modeling decomposed into quartiles is made to the conditional distribution of proficiency. The results proved to be favorable to the performance of students from private schools, in an increasing way, for the quartiles, and who have better family socioeconomic conditions such as income and a mother with higher education. Evidence that demands public policies to equalize the possibilities of access to higher education as a way to minimize the growing educational inequalities.

Keywords: School performance. Enem. Quantile regression.

\footnotetext{
${ }^{1}$ Mestrando em Organizações e Mercados pela Universidade Federal de Pelotas (UFPel). http://lattes.cnpq.br/2622190250950634. http:// orcid.org/0000-0002-5295-7969. torresronaldo@yahoo.com.br

${ }^{2}$ Graduando em Ciências Econômicas pela Universidade Federal de Santa Maria (UFSM). Bolsista de Iniciação Científica do CNPq. http:// lattes.cnpq.br/8616489795438914. http://orcid.org/0000-0003-2854-1856. mateus.mpereira@hotmail.com

${ }^{3}$ Doutor em Economia Aplicada pela Universidade Federal de Viçosa (UFV). Professor da Universidade Federal de Santa Maria (UFSM). http://lattes.cnpq.br/9794436610539367. http://orcid.org/0000-0002-1019-4414. reisolibender@yahoo.com.br

${ }^{4}$ Mestranda em Economia e Desenvolvimento pela Universidade Federal de Santa Maria (UFSM). http://lattes.cnpq.br/1820164121867898. http://orcid.org/0000-0001-9131-5996. fernandacl32@hotmail.com
} 
O Exame Nacional do Ensino Médio (Enem) teve seu início no ano de 1998, tendo como principal objetivo a avaliação da Educação Básica, principalmente da escola pública, com a finalidade de gerar informações à formulação de políticas governamentais. Conforme discute Dias (2006), todavia, o exame assume também a finalidade de avaliar o desempenho do aluno ao término da escolaridade básica para aferir o desenvolvimento de competências fundamentais ao exercício pleno da cidadania.

Posteriormente, a nota do Enem passou a ser utilizada como forma de ingresso no Ensino Superior na maioria das universidades públicas. Desta forma a prova, que nos primeiros anos não possuía grande adesão dos participantes, passou a ter papel fundamental para os alunos que objetivam ingressar no Ensino Superior, conforme apontado pelo Instituto Nacional de Estudos e Pesquisas Educacionais Anísio Teixeira (Inep) (INEP, 2019).

Diante disso, a nota obtida passou a ser utilizada tanto em processo de seleção para ingresso em cursos do Ensino Superior de universidades públicas, por meio do Sistema de Seleção Unificada (Sisu), como também para universidades privadas, por meio do Programa Universidade para Todos (Prouni), que concede bolsas de estudo integral ou parcial em cursos de Graduação ou formação específica e, ainda, para a inserção no Fundo de Financiamento Estudantil (Fies), que oferece financiamento do Ensino Superior em instituições privadas.

Embora a finalidade comum seja o ingresso no Ensino Superior, as condições formativas para este ingresso são distintas, sobremaneira quando se relacionam às redes de Ensino Fundamental e Médio, as quais possuem amplas desigualdades. Para o ano de 2016, das dez primeiras escolas do Rio Grande do Sul que apresentaram melhores colocações, apenas duas eram de escolas públicas; em contraponto, apesar de a maior parte dos alunos participantes da prova do Enem serem pertencentes às escolas de natureza pública, a concentração dos melhores desempenhos está no sistema educacional de natureza privada (FOLHA DE SÃO PAULO, 2016).

Conquanto a concentração das melhores colocações esteja nas escolas de natureza privada, o Estado do Rio Grande do Sul historicamente tem apresentado indicadores educacionais elevados também no ensino público, tanto para o Ensino Fundamental quanto para o Médio. Destaca-se ainda que em alguns anos o Estado apresentou indicadores superiores à média nacional, conforme a Confederação Nacional de Munícipios (CONFEDERAÇÃO,...2009).

A partir do atual modelo de avaliação para ingresso no Ensino Superior e do debate acerca de seus resultados, buscou-se evidências quanto à ocorrência de diferenças entre o ensino público e o ensino privado, para o Estado do Rio Grande do Sul, a partir do desempenho dos alunos no Enem, no ano de 2017. Complementarmente, procurou-se analisar quais fatores são condicionantes deste processo, de modo a observar se este modelo se adéqua à utilização de sistemas de cotas para o ingresso no Ensino Superior.

A utilização de políticas de ação afirmativa, caso das cotas sociais, sabidamente facilita a entrada de estudantes em Instituições de Ensino Superior que atendam aos critérios estipulados por lei. Para discutir a efetividade desta política, entretanto, é indispensável compreender se essas cotas geram equidade de oportunidades entre os 
alunos da rede pública de educação, comparando-os aos da rede privada, levando em consideração fatores econômicos, sociais e familiares. Discussão que se respalda na importância à efetividade das políticas públicas, sobretudo a educacional, estruturada em seus objetivos e resultados, tanto ao fornecer evidências à avaliação quanto para fundamentar proposições de ajustes no sistema de seleção, condições essas que tornam estas análises atemporais, mesmo em processos seletivos padronizados, caso do Enem.

Problemática que baseou diversos estudos, como o de Nogueira e Alencar (2012 ), que utilizaram como base o Programa Internacional de Avaliação de Alunos (Pisa) para analisar como questões parentais influenciam na qualidade do desempenho dos filhos no exame Pisa. Nesta mesma linha, encontra-se o trabalho de Moraes e Belluzo (2014), que analisaram o diferencial do desempenho na prova do Sistema Nacional de Avaliação da Educação Básica (Saeb) entre escolas de natureza pública e privada a partir da utilização da decomposição por quantis das notas da prova do Saeb. Comum a ambos está a relevância destas análises para propor melhorias ao sistema educacional, bem como para a formulação de políticas públicas.

Frequentemente os estudos analisam o Brasil em sua extensão territorial total, caso dos citados estudos de Nogueira e Alencar (2012) e Moraes e Belluzo (2014), porém as distâncias geográficas não só caracterizam as regiões como também revelam as desigualdades educacionais nos distintos Estados do país (RIGOTTI, 2001; MEDEIROS; OLIVEIRA, 2014). Neste sentido, por ser o Rio Grande do Sul um Estado com histórico de elevados níveis educacionais, analisar se as evidências locais convergem para o padrão nacional possibilitam também discutir os efeitos da política pública em diferentes estruturas sociais e econômicas.

Assim, considerando que não se dispõe de um estudo detalhado do desempenho dos participantes da prova do Enem para o Estado do Rio grande do Sul, como também há apenas estudos relacionados à mudança da política de avaliação do Enem a partir de 2009, busca-se neste estudo aferir o desenvolvimento das competências e habilidades fundamentais ao exercício da cidadania, como é abordado nos estudos de Costa-Beber (2014), em que destacam tanto o novo método de avaliação como a expansão do uso da nota do Enem para o ingresso no Ensino Superior pelas instituições localizadas na Região Sul do Brasil.

$\mathrm{O}$ artigo está estruturado em cinco seções, contando com esta introdução. Na segunda é apresentada a revisão de literatura. Em seguida, na terceira, é exposta a metodologia empregada no estudo, a qual está dividida em dois tópicos: o primeiro descreve a fonte e a base de dados enquanto o segundo relata o modelo empírico. A quarta destina-se à apresentação dos resultados, estando dividida nos tópicos: análise descritiva e estimativas. A última dedica-se às conclusões do trabalho.

\section{REVISÃO DA LITERATURA}

O desempenho escolar faz parte de uma discussão complexa que se estende desde as condições familiares até o modelo de política educacional adotado, envolvendo contextos sociais, econômicos e institucionais. 
A decisão sobre o ingresso em escolas de natureza pública ou privada é resultado de fatores como renda e qualidade. Conforme Moraes e Belluzzo (2014), isso dificulta a mensuração entre o diferencial do desempenho escolar entre alunos, dado que aqueles de alta renda já possuem precondições para obter um desempenho melhor. Outro aspecto se relaciona aos fatores não observáveis ou que não constam na base de dados para a escolha. Nos Estados Unidos, por exemplo, a maioria das escolas de natureza privada é católica, podendo ser um fator de decisão importante para essa população, sem relação direta com a renda. Fatores não captados, como os exemplificados, podem gerar um possível viés nos resultados, dificultando a comparação direta entre o tipo de escola (MORAES; BELLUZZO, 2014).

Ampliando o espectro analítico, Black e Devereux (2011) examinaram quais características que os pais possuem que podem influenciar na educação dos filhos. Dois fatores foram destacados: o primeiro indica que o nível de escolaridade dos pais tem relação direta com a renda e, por isso, influencia as condições ambientais, como acesso a melhores materiais, cursos e escolas melhores, o segundo relaciona-se ao ambiente compartilhado, em que pais com maior escolaridade induzem os filhos a buscar melhores resultados educacionais.

Colaborando, Machado et al. (2008) evidenciaram que a escolaridade da mãe com Ensino Superior torna o desempenho do aluno melhor. Além disso, também são considerados outros fatores, como o maior acesso a livros, o que amplia o desempenho de alunos nos resultados obtidos nas avaliações de Matemática, sendo estes fatores importantes para a redução no índice de reprovação. Estes fatores, entretanto, não diminuem a importância de políticas públicas relacionas ao desempenho, dado que haveria correlação positiva entre condições familiares e a qualidade das escolas.

Utilizando-se de um modelo de regressão quantílica hierárquica, Barbetta, Andrade e Tavares (2018) focaram em fatores relacionados à escola, como a maneira de o professor se portar em sala de aula. Isso faz com que os alunos venham a ter diferentes desempenhos, pois o fato de o professor se preocupar com os deveres de casa do aluno faz com que este tenha um desempenho melhor. Também foi verificado que o ambiente socioeconômico em que o aluno está inserindo tem maior impacto no seu desempenho, tornando-o mais elevado. Ainda foi evidenciado que o fator gênero também tem peso no desempenho, dado que alunos do gênero feminino mostraram melhores resultados em Língua Portuguesa e alunos do gênero masculino obtiveram melhor desempenho em Matemática.

Outra dimensão desta discussão refere-se às diferenças étnicas entre brancos e não brancos, as quais foram abordadas por Alves e Soares (2002), que obtiveram resultados que mostram que as diferenças entre eles resultariam do retrospecto de desigualdades sociais que são anteriores à própria escola; condição que demonstra que as desigualdades sociais enfrentadas pelos alunos possuem alguma relação com a herança histórica de desigualdade social.

Ainda sobre a relação da herança histórica de desigualdade social, o Brasil passa a adotar a "lei das cotas" que, de acordo com Teles (2015), seriam medidas tomadas para reduzir os efeitos das desigualdades sociais que são anteriores à própria escola. Todos são iguais perante a lei, mas a História do Brasil privou certo fragmento da sociedade de obter conhecimento intelectual e desenvolvimento social, fato que ocasionou relevante 
inferiorização na capacidade dessa parcela de ingressar no Ensino Superior em relação à outra parcela proveniente das elites. Logo, políticas de ação afirmativa, caso das cotas, tornam-se necessárias para a redução dessas desigualdades sociais.

Comparações entre escolas de natureza pública e privada também pautaram o estudo de Albernaz, Ferreira e Franco (2002), que, por meio da aplicação de modelos hierárquicos, controlando o nível socioeconômico, encontraram evidências de que quanto maior o nível socioeconômico da escola, melhor o seu desempenho. Isso favorece as escolas de natureza privada na obtenção de melhores resultados em termos de desempenho. E ainda, os resultados apontaram que, após o controle do nível socioeconômico, atributos pessoais como raça e gênero ainda mostraram significância para a explicação dos diferenciais de desempenho escolar.

\section{METODOLOGIA}

\section{Modelo Empírico}

A modelagem de regressão quantílica é empregada, entre outras aplicações, na presença de outliers, situação que caracteriza estrutura de dados de elevada heterogeneidade, justificado pelo fato de esta estimativa ser robusta a tal estrutura (GREENE, 2003 ). Também é a metodologia indicada para analisar diferentes níveis de desempenho e seus principais determinantes, condição que se alinha ao objetivo proposto. Neste sentido, a aplicação de regressão quantílica pode fornecer insights melhores para a comparação do desempenho entre escolas de natureza pública e privada.

O modelo de regressão quantílica é uma extensão do modelo de regressão linear clássico e sua primeira aplicação foi realizada por Koenker e Bassett (1978), quando verificaram que o modelo apresenta vantagens em relação ao modelo clássico, pois permite a análise em todos os quartis da amostra. Destaca-se que, em análises que envolvem grandes disparidades na distribuição entre os quartis, essa modelagem apresenta uma melhor performance, diferente dos demais modelos que tendem a oferecer resultados de tendência central.

Estruturalmente, regressão quantílica permite analisar a associação contemporânea entre a variável dependente proficiência, definida a partir das notas obtidas no exame, com as variáveis explicativas nos diversos quantis da distribuição condicional. Isto permite um mapeamento mais completo das variáveis individuais dos alunos sobre as proficiências, analisado em cada quartil correspondente. Em termos formais, essa metodologia é compreendida como uma extensão dos quartis amostrais que assume a forma expressa em (1):

$$
\begin{aligned}
& \min _{b \in \mathbb{R}} n^{-1}\left\{\sum_{t \in\left\{t: y_{t} \geq x_{t} \beta\right\}} \theta\left|y_{t}-x_{t} \beta\right|+\sum_{t \in\left\{t: y_{t}<x_{t} \beta\right\}}(1-\theta)\left|y_{t}-x_{t} \beta\right|\right\}= \\
& \min n^{-1} \sum_{i=1}^{n} P_{\theta}\left(y_{t}-x_{t} \beta\right) \\
& \quad \text { em que } P \text { é a função "check" que é definida por: }
\end{aligned}
$$

$$
P_{\theta}(u)=\left\{\begin{array}{cc}
\theta u, & u \geq 0 \\
(\theta-1) u, & u<0
\end{array}\right.
$$


sendo que a função $P_{\theta}$ é multiplicada pelos resíduos maiores ou igual a zero por $\theta$ e por $(\theta-1)$ caso contrário, em que o $\theta$ é o quartil da análise que "assume valor $\theta=1 / 2$ quando analisa-se para a mediana e pode-se assumir outros valores para cada quartil de análise" isso permite comparar os resultados dentro da própria estimação, quando os resultados obtidos apresentam uma distribuição heterogênea, distribuição essa diferente para os níveis de quartis "conforme as proficiências dos alunos vêm a sofrer um maior impacto nos extremos, devido a melhores condições de ensino", de acordo com o que expõem Silva e Júnior (2006).

Em uma etapa seguinte aplicou-se o teste de hipótese de Wald para comparar a igualdade dos coeficientes estimados considerando os diferentes quartis da distribuição. Com isso, buscou-se observar se o desempenho dos coeficientes apresenta diferenças nos quartis. $O$ referido teste tem como a hipótese nula que os coeficientes são iguais entre os quartis, em oposição à hipótese alternativa que apresenta diferenças entre os quartis, conforme encontrado em Cameron e Trivedi (2009).

A partir dessas definições teóricas, formulou-se o modelo analítico, conforme exposto na equação em (3):

$\log (N T)=\beta_{0}+M B \beta_{1}+I D \beta_{2}+I D^{2} \beta_{3}+E . P . \alpha_{1}+R . F \alpha_{2}+S E \alpha_{3}+N E \alpha_{4}+M . S \alpha_{5}+$

A.I. $\alpha_{6}+u_{i}$

Essa especificação é estruturada na forma de um modelo log-lin, cuja variável dependente $\log (N T)$ corresponde às notas totais em logaritmo, enquanto as variáveis acompanhadas por $\beta$ são variáveis que desempenham a função numérica, já as acompanhadas por $\alpha$ são variáveis que relacionam a qualidade, tendo elas representação quantitativa binária, e definição de dummies. A partir destas definições, o Quadro 1 apresenta as variáveis considerando o efeito esperado sobre a variável dependente, proficiência dos alunos (notas).

Quadro 1 - Variáveis e sinais esperados

\begin{tabular}{|l|c|c|}
\hline \multicolumn{1}{|c|}{ Variável } & Sigla & Sinal Esperado \\
\hline Membros & $M B$ & $(-)$ \\
\hline Idade & $I D$ & $(+)$ \\
\hline Idade $^{2}$ & $I D^{2}$ & $(-)$ \\
\hline Aluno escola pública & $E . P$. & $(-)$ \\
\hline Renda familiar & $R . F$ & $(-) /(+)$ \\
\hline Sexo & $S E$ & $(-)$ \\
\hline Cor negra & $N E$ & $(+)$ \\
\hline Mãe com Ensino Superior & $M . S$ & $(+)$ \\
\hline Acesso à Internet & $A . I$. & \\
\hline
\end{tabular}

Fonte: Elaboração própria (2019). 
O modelo aplicado avalia o desempenho em quartis, caso em que o primeiro $(0,25)$ relaciona os $25 \%$ das proficiências mais baixas; o quartil $(0,5)$ analisa a mediana das proficiências e o quartil $(0,75)$ examina quais características têm as observações que estão entre os $25 \%$ com melhor proficiência na prova.

Complementando a análise, com o proposto de dinamizar a modelagem, foi calculando o turnaround point (ou ponto de inversão) que indica um valor máximo de uma função quadrática a partir da derivada parcial em relação à idade. O efeito esperado pode ser expresso por $\partial d y / \partial d x=\beta_{2}+2 \beta_{3}$. Obtendo $\beta_{2}>0$ e $\beta_{3}<0$ tem-se o ponto máximo da função dado por $\left(\frac{\beta_{2}}{2 \beta_{3}}\right)$, em módulo; caso contrário, com $\beta_{2}<0$ e $\beta_{3}$. $>0$ então a função quadrática tem um ponto mínimo.

\section{Fonte, Dados e Variáveis}

A base de dados utilizada encontra-se disponível no site do Inep, referente ao Enem, realizado no ano de 2017. Esta base contém informações referente ao desempenho e também dados sobre as condições estruturais, econômicas e familiares do aluno.

Em termos de observações, foram considerados para a análise somente os alunos que realizaram a prova, com a condição de que não tenham zerado em nenhum dos cinco quesitos de avaliação. A exclusão do modelo dos alunos que não tenham tirado nota (ou tenham zerado), deve-se ao fato de a prova ter um alto índice de não comparecimento. Conforme o Inep, no primeiro dia de provas a abstenção atingiu 30,2\% dos inscritos (INEP, 2017).

A partir desse critério, do total de alunos inscritos para realizar o Enem no Estado do Rio Grande do Sul em 2017, foram considerados somente aqueles que compareceram a quatro provas objetivas e fizeram a redação. Assim sendo, a amostra limitou-se a 208.842 participantes e deste total foram excluídos aqueles alunos que não compareceram a alguma prova. Ao final, após os critérios de exclusão, o número de observações totalizou 86.131 , equivalente a $29,19 \%$ do total dos alunos inscritos no exame.

Para a estimativa do modelo exposto em (1) foram consideradas variáveis de natureza social e econômica além da pontuação obtida pelo aluno. A descrição e a definição deste conjunto de variáveis encontram-se detalhadas no Quadro 2.

Quadro 2 - Variáveis e definição

\begin{tabular}{|l|l|}
\hline Proficiência & $\begin{array}{l}\text { Variável que relaciona a média aritmética das notas referentes a } \\
\text { Linguagens, Ciências Humanas, Ciências da Natureza, Matemática e } \\
\text { redação. Aplicou-se logaritmo para posterior análise. }\end{array}$ \\
\hline Membros & $\begin{array}{l}\text { Variável numérica que relaciona a quantidade de pessoas que moram na } \\
\text { residência. }\end{array}$ \\
\hline Idade & Variável numérica idade do indivíduo que fez a prova. \\
\hline Aluno escola pública & $\begin{array}{l}\text { Dummy para escola pública. } 1 \text { para o aluno que cursou ensino médio só } \\
\text { em escola pública e } 0 \text { caso contrário. }\end{array}$ \\
\hline Renda familiar & $\begin{array}{l}\text { Dummy para renda familiar. } 0 \text { para renda superior a R\$ 1.405,50 e } 1 \text { para } \\
\text { renda inferior a R\$ } 1.405,50 .\end{array}$ \\
\hline Sexo & Dummy para o gênero. 0 para o sexo masculino e 1 para o sexo feminino. \\
\hline Cor negra & Dummy para cor/raça. 1 para cor negra e 0 para as demais. \\
\hline Mãe com Ensino Superior & $\begin{array}{l}\text { Dummy para mãe com ensino superior. } 1 \text { para mãe que possui Ensino } \\
\text { Superior completo e } 0 \text { para as demais. }\end{array}$ \\
\hline Acesso à Internet & $\begin{array}{l}\text { Dummy para o acesso à Internet. } 1 \text { se a residência do aluno possui acesso } \\
\text { à Internet e } 0 \text { para o caso de ele não possuir acesso à Internet. }\end{array}$ \\
\hline
\end{tabular}

Fonte: Elaborado pelos autores (2019). 
Nesta representação a presença do efeito desigualdade é obtido a partir da inclusão das variáveis dummies, as quais permitem identificar quais as relações sociais, econômicas e estruturais que exercem influência no desempenho da proficiência no Enem. Ainda a inclusão destas variáveis deu-se a partir do argumento de que as condições sociais contribuem para que o participante obtenha melhores notas. Seguindo a proposta de Moraes e Belluzzo (2014), as variáveis qualitativas permitem captar o quanto uma característica melhora o desempenho.

\section{RESULTADOS}

\section{Análise Descritiva}

O conjunto de dados que compõem o Enem agrupa informações quanto às questões de desempenho das escolas de natureza pública e privada. Partindo da proposta de identificar os determinantes e os diferenciais das proficiências dos alunos de ambos os grupos escolares, faz-se necessário inicialmente discutir as estatísticas descritivas dos dados, as quais estão apresentadas na Tabela 1.

Tabela 1 - Estatísticas descritivas dos dados dos alunos de escolas de natureza pública e privada

\begin{tabular}{lccccc}
\hline Tipo de escola & \% de alunos & $\begin{array}{c}\text { Pontuação } \\
\text { média }\end{array}$ & $\begin{array}{c}\text { Desvio } \\
\text { padrão }\end{array}$ & $\begin{array}{c}\text { Menor } \\
\text { proficiência }\end{array}$ & $\begin{array}{c}\text { Maior } \\
\text { proficiência }\end{array}$ \\
\hline Pública & $81,01 \%$ & 529,08 & 60,28 & 306,02 & 821,78 \\
\hline Privada & $18,99 \%$ & 585,88 & 74,62 & 348,56 & 813,34 \\
\hline
\end{tabular}

Fonte: Elaborada pelos autores a partir do Enem (2017).

Observa-se ligeira diferença entre o desempenho dos alunos das escolas de natureza pública e privada, equivalente a 56,8 pontos; entretanto, a escola de natureza pública apresenta uma participação muito maior que a escola de natureza privada, com $81 \%$ dos participantes do Enem oriundos da rede pública de educação. Em termos de desempenho, o aluno de escola pública obteve proficiência equivalente a 529,08 pontos, 9,69\% abaixo do desempenho médio dos alunos de escola privada, os quais obtiveram média de 585,88 pontos. Esta diferença mostra-se relevante considerando a menor participação da rede particular de educação.

Considerando a dispersão dos dados, o desvio padrão das proficiências dos alunos da escola de natureza pública ficou em 60,28 pontos, enquanto que a dispersão das proficiências dos alunos da escola de natureza privada foi maior, de 74,62 pontos. Esta variação maior da escola particular, indicativo de proficiências mais dispersas e heterogêneas, pode aproximar mais os resultados entre os alunos dos dois sistemas de educação.

Assim, para aprofundar tais resultados, apresenta-se a estimativa de densidade de Kernel, que é uma forma não paramétrica de estimar a função densidade probabilidade de uma variável aleatória, para as variáveis rede de ensino, renda e escolaridade da mãe. Esta medida, ao avaliar a diferença entre as densidades de proficiências, fornece maior robustez que a simples comparação entre médias e variâncias. 
A Figura 1 apresenta os resultados para a distribuição de proficiências dos ensinos público e privado. Observa-se que as notas obtidas pela rede pública tiveram uma densidade inferior, próxima dos 500 pontos, enquanto que aquelas obtidas pela rede privada de ensino apresentaram densidade das notas próxima dos 600 pontos.

Figura 1 - Distribuição de Kernel do diferencial de proficiências das escolas de natureza pública e privada

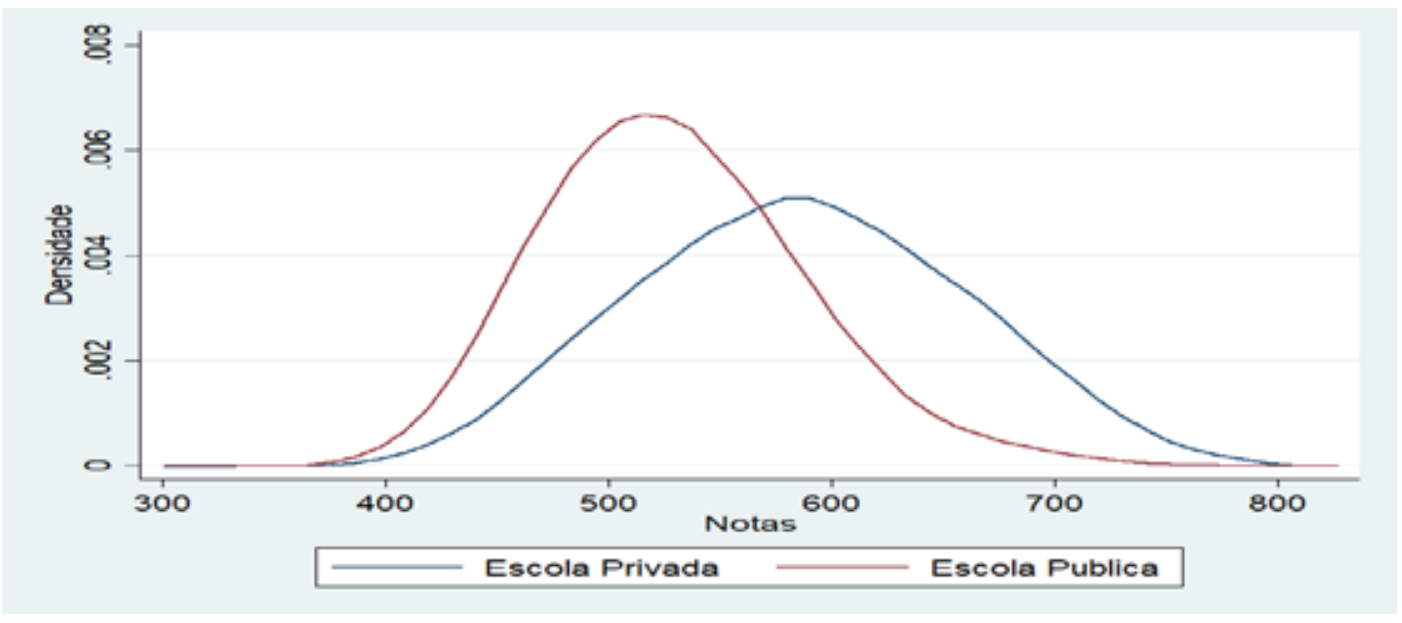

Fonte: Elaborada pelos autores com base nos resultados da pesquisa (2019).

O desempenho inferior dos alunos da escola de natureza pública deve-se, em grande medida, às melhores condições de ensino oferecidos pelas escolas de natureza privada, resultado que se assemelha ao obtido por Albernaz, Ferreira e Franco (2002), quando avaliaram o desempenho dos alunos de ambas as redes de ensino, utilizando a base de dados nacionais dos resultados da pesquisa do Sistema de Avaliação da Educação Básica, do ano de 1999.

Nesta discussão, a renda representa outro fator relevante, dado que amplia o distanciamento do desempenho escolar ao apresentar diferença expressiva quando analisada a distribuição das proficiências, conforme verifica-se na Figura 2.

Figura 2 - Distribuição de Kernel do diferencial de renda das escolas de natureza pública e privada

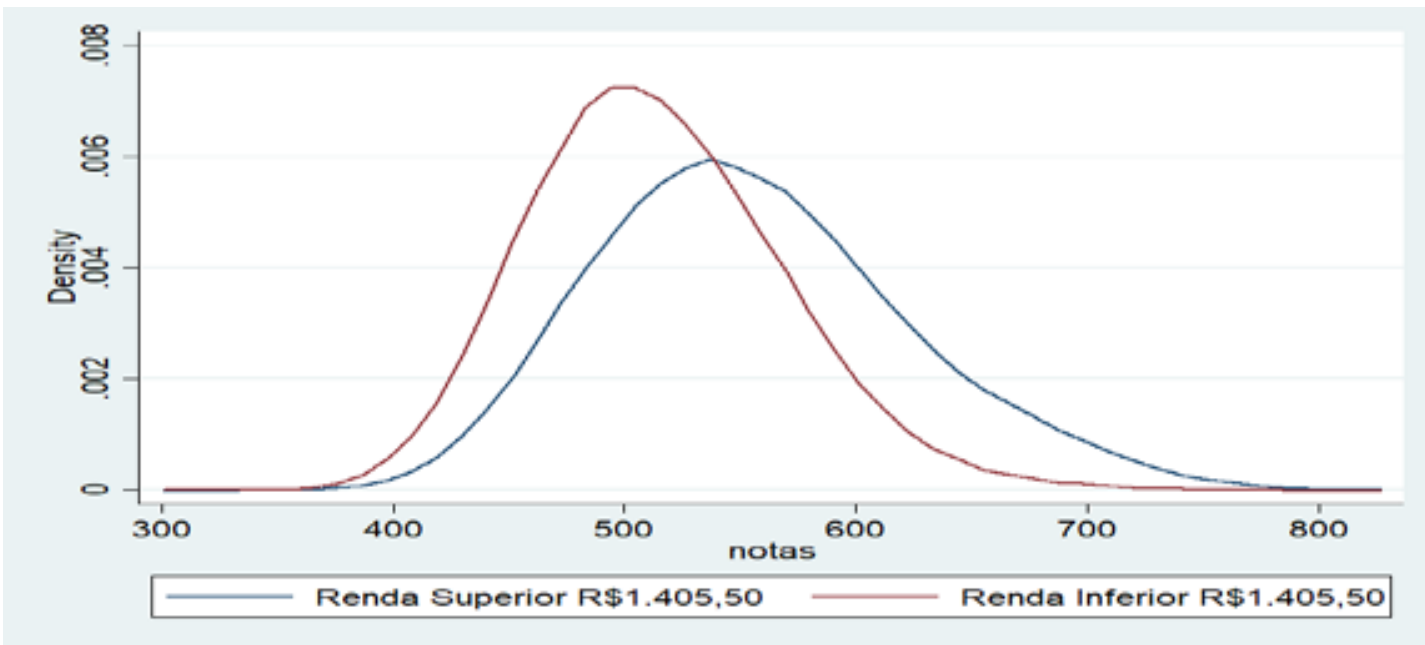

Fonte: Elaborada pelos autores com base nos resultados da pesquisa (2019). 
Da mesma forma que ocorreu diferença da rede pública de ensino para a rede privada, também se observou uma distribuição das proficiências maiores em favor dos que informaram renda mensal familiar superior a $\mathrm{R} \$ 1.405,50$ comparativamente aos que declararam renda inferior a este limite. Este resultado corrobora as evidências de Silva, Morino e Sato (2014), os quais identificaram a renda familiar baixa e a escolaridade dos pais de nível primário como fatores que diminuem o desempenho do aluno. Ainda, analisando os resultados quanto à rede escolar e ao nível de renda, parece razoável assumir que estes dois fatores conjuntamente determinam condições para um melhor desempenho escolar (MORAES; BELUZZO, 2014).

Complementando, apresenta-se a distribuição de frequências dos alunos considerando a escolaridade da mãe, conforme Figura 3. Observa-se que a distribuição mostrou-se favorável ao desempenho, em termos de proficiências, daqueles alunos cuja mãe tem formação em nível superior comparativamente àqueles que a mãe não possui esse nível de escolarização. Este resultado corrobora a discussão de Corti (2013), que demonstra que a escolaridade da mãe é um dado importante na análise do perfil socioeconômico em virtude da forte relação entre pobreza e exclusão escolar.

Figura 3 - Distribuição de Kernel do nível educacional das mães dos alunos das escolas de natureza pública e privada

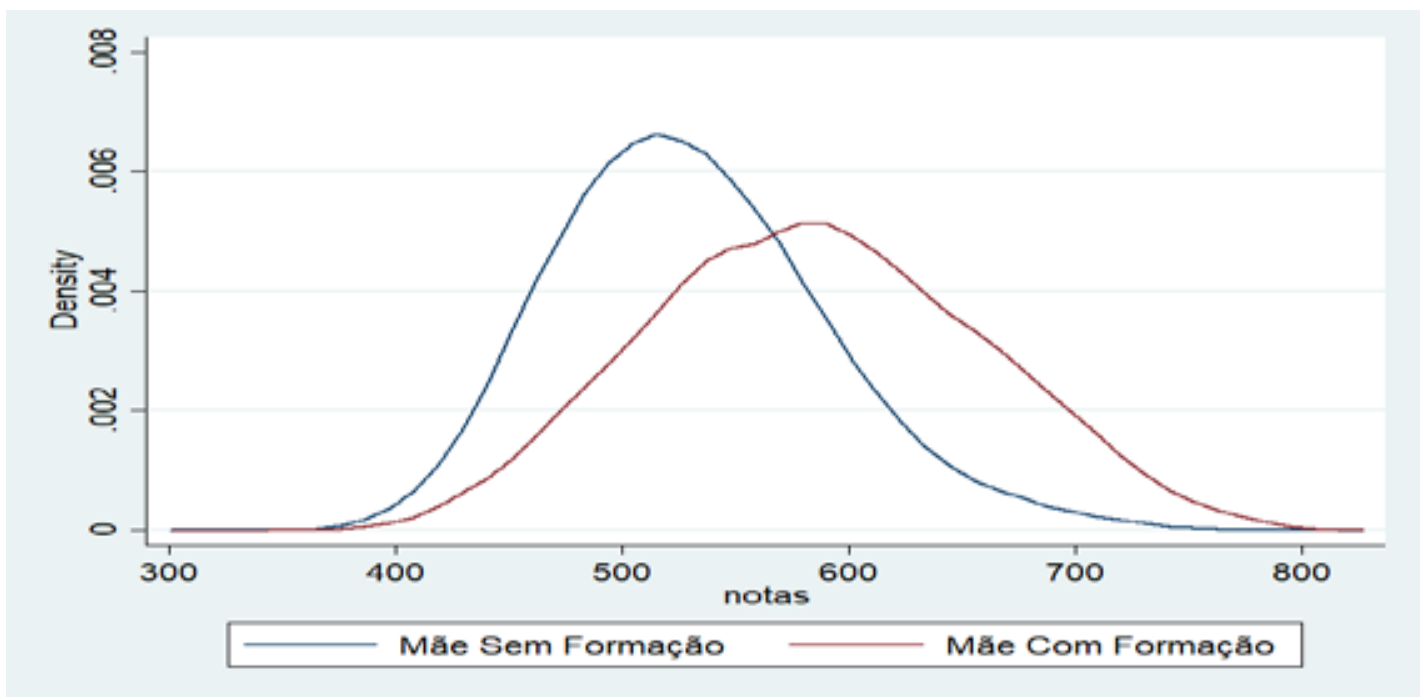

Fonte: Elaborada pelos autores com base nos resultados da pesquisa (2019).

Nesta mesma linha, Franco e Menezes (2012) verificaram relação entre renda, Ensino Superior e escolaridade do aluno ao considerar a proporção de mães com Ensino Superior, indicando um elevado status socioeconômico da mãe, o que propicia ao aluno melhores condições de acesso a materiais e educação de melhor qualidade. Assim sendo, os alunos pertencentes a famílias com maior poder aquisitivo apresentaram níveis de proficiência mais altos, demonstrando elevada estratificação social no sistema educacional brasileiro.

Complementando, conforme argumentam Soares e Collares (2006), é possível perceber que os alunos integrantes de uma estrutura familiar com vínculos saudáveis de relacionamento apresentam melhores desempenhos, considerando a abertura para conversar com os seus pais sobre a vida escolar e também a cultura familiar à qual pertence. 
A partir destas relações constata-se que o perfil dos alunos que obtiveram as maiores proficiências no Enem, no Rio Grande do Sul, no ano de 2017, invariavelmente estudam em escolas de natureza privada, possuem renda mensal familiar superior a $\mathrm{R} \$ 1.405,50$ e a mãe possui formação no Ensino Superior. Resultados que, embora intuitivos, confirmam as evidências encontradas nos estudos de Machado et al. (2008) e Black e Devereux (2011), em que o fato de os pais possuírem Ensino Superior os leva a ter uma melhor renda e, consequentemente, o acesso a melhores materiais. Logo, esse ambiente familiar estimula os filhos a buscarem por melhores resultados educacionais.

\section{Determinantes do Desempenho no Enem dos Alunos do Rio Grande do Sul para o ano de 2017}

Os resultados das estimativas dos determinantes do desempenho dos alunos do Rio Grande do Sul no Enem, no ano de 2017, obtidos a partir da aplicação da regressão quantílica, encontram-se detalhados na Tabela 2. De forma geral, observa-se que as estimativas apresentaram os sinais esperados e foram estatisticamente significativas, como também se alinham às evidências encontradas por Moraes e Belluzzo (2014), quanto à diferença de desempenho de escolas de natureza privada e pública.

Tabela 2 - Determinantes do desempenho dos participantes da prova do Enem do Estado do Rio Grande do Sul em 2017

\begin{tabular}{|c|c|c|c|}
\hline Variáveis & QREG (0.25) & QREG (0.50) & QREG (0.75) \\
\hline Membros & $-0,007175^{* * *}$ & $-0,007348 * * *$ & $-0,007209 * * *$ \\
\hline Idade & $0,000856 * * *$ & $0,001242 * * *$ & $0,001581 * * *$ \\
\hline Idade $^{2}$ & $-0,000027^{* * *}$ & $-0,000033^{* * *}$ & $-0,000039 * * *$ \\
\hline Aluno escola pública & $-0,059586 * * *$ & $-0,068721 * * *$ & $-0,073296 * * *$ \\
\hline Renda familiar & $-0,043717^{* * *}$ & $-0,046496 * * *$ & $-0,048032 * * *$ \\
\hline Sexo & $-0,009070 * * *$ & $-0,014254 * * *$ & $-0,016004 * * *$ \\
\hline Cor negra & $-0,032658 * * *$ & $-0,036064 * * *$ & $-0,040040 * * *$ \\
\hline Mãe com Ensino Superior & $0,050134^{* * *}$ & $0,054954 * * *$ & $0,059049 * * *$ \\
\hline Acesso à Internet & $0,029172 * * *$ & $0,032160 * * *$ & $0,034197 * * *$ \\
\hline Intercepto & $6,270658^{* * *}$ & $6,348963^{* * *}$ & $6,420657^{* * *}$ \\
\hline Pseudo $\mathrm{R}^{2}$ & 0,0884 & 0,117 & 0,1442 \\
\hline
\end{tabular}

$* * *, * * \mathrm{e}^{*}$ indica que a hipótese nula é rejeitada ao nível de significância de $1 \%, 5 \%$ e $10 \%$ respectivamente.

Fonte: Elaborada pelos autores com base nos resultados da pesquisa (2019).

Em termos de distribuição de frequências, no quartil representativo dos $25 \%$ das proficiências mais altas, o aluno de escola de natureza pública apresentou desempenho $7,33 \%$ menor que o aluno de escola de natureza privada. Igualmente, quando se analisa o quartil dos $25 \%$ das proficiências mais baixas, o aluno de escola de natureza pública ainda apresentou desempenho inferior ao aluno de escola de natureza privada, porém a diferença diminui, ficando em 5,96\%. Já quando se analisa a mediana das proficiências, o aluno de escola de natureza pública obteve desempenho inferior de 6,87\% comparado ao aluno da escola de natureza privada. 
A variável relacionada à condição financeira (renda familiar) indicou que alunos que possuem uma renda inferior a $\mathrm{R} \$ 1.405,50$ apresentaram um desempenho 4,37\% inferior no quartil $(0,25)$ quando comparados àqueles que informaram renda superior a este limite. A diferença foi ainda maior quando se compara o quartil $(0,75)$, que relaciona as melhores proficiências, quando o desempenho foi cerca de $4,80 \%$ menor para aqueles alunos que possuem menores rendas.

Estes resultados confirmam as evidências encontradas nos trabalhos de Madeira (2006), Travitzki (2013) e Zacchi (2016), os quais concluíram que o fator econômico, por oferecer condições de estudo mais adequadas, como acesso a melhores materiais, cursos e escolas, se constitui invariavelmente em um determinante para o melhor desempenho escolar. De igual forma, Travitzki (2013) ao analisar o resultado do Enem para o Brasil, no ano de 2009, atribui aos condicionantes socioeconômicos, como a renda e a escolaridade dos pais, pelo menos $75 \%$ da média do desempenho obtido pelos estudantes nas escolas em que, no mínimo, dez estudantes prestaram o Exame Nacional do Ensino Médio.

Analisando os aspectos sociais familiares, o aluno obtém melhor desempenho (proficiência) quando a mãe possui formação no Ensino Superior, independentemente do quartil analisado. Estes valores indicam que o fato de a mãe ter formação no terceiro grau favorece o melhor desempenho quando analisado no quartil $(0,75)$, cuja estimativa foi 5,9\% superior quando comparado aos alunos que não têm mãe com Ensino Superior. Para o quartil $(0,25)$, o desempenho daqueles que a mãe possui Ensino Superior é menor, ficando em cerca de $5,0 \%$, enquanto que na mediana o desempenho foi $5,49 \%$ maior que os demais.

Essas evidências alinham-se àquelas obtidas por Black e Devereux (2011), os quais concluíram que o nível de educação dos pais possui influência no desempenho dos filhos, destacando que, quanto maior o nível educacional dos pais, melhor o desempenho dos filhos. Ainda demonstraram que as condições intergeracionais refletidas nos déficits educacionais dos pais, sobretudo da mãe, não têm sido corrigidos pelos sistemas de avaliação vigentes (MADEIRA, 2006), de forma que as escolas não têm conseguido compensar as desvantagens com que estes estudantes chegam ao sistema de ensino (ZACCHI, 2016).

Diferente dos resultados anteriores, o sexo dos candidatos apresentou relação negativa e significativa, entretanto as diferenças entre os quartis foram reduzidas. Essa relação inversa indica que as alunas que prestaram o Enem, em média, obtiveram proficiências inferiores em todos os recortes amostrais, com maior distanciamento no quartil $0,75(1,60 \%)$, enquanto que para o quartil 0,25 o diferencial de proficiência foi o menor, de $0,9 \%$.

Estes resultados podem ser justificados, conforme discutido por Barbetta, Andrade e Tavares (2018), pelo desempenho em disciplinas específicas do componente curricular, caso das disciplinas de Matemática e Língua Portuguesa. Na primeira disciplina o desempenho é maior para homens, já na segunda prevalecem melhores resultados para mulheres. Assim sendo, como a variável dependente é a média da proficiência de todas áreas do conhecimento do Enem, a interpretação deve ser em termos de resultado médio de todo o componente curricular, o qual se mostrou maior para os homens. 
À variável acesso à Internet o efeito estimado foi positivo e significativo para todos os-quartis. Esta variável, todavia, refletiu em maior diferencial de desempenho para o quartil $(0,75)$, que relaciona os $25 \%$ das melhores proficiências. Para este quartil o diferencial de desempenho foi de $3,41 \%$ para os alunos com acesso à Internet comparativamente àqueles que não possuem. Já para o quartil relacionado ao desempenho dos $25 \%$ que obtiveram as menores proficiências, o acesso à Internet indicou um resultado maior de 2,91\%, enquanto que à mediana o acesso à Internet resulta em desempenho maior em 3,21\%.

As condições tanto de qualidade quanto de conteúdo fornecidas pelo acesso à Internet, traduzida na possibilidade de pesquisas e troca de informações, relacionaram-se positiva e significativamente com a proficiência no Enem, com resultados variando de $2,91 \%(0,25)$ a $3,42 \%(0,75)$, respectivamente. Tais evidências indicam que o maior acesso à Internet possibilita, além do melhor uso desta ferramenta, a busca por cursos e materiais didáticos, melhorando o desempenho educacional. Estas evidências corroboram os resultados de Machado et al. (2008), os quais argumentam que fatores como o maior acesso a livros ou até uma maneira mais fácil de encontrar material didático melhora o desempenho educacional de alunos.

A quantidade de membros da família também apresenta papel importante no desempenho escolar, pois famílias maiores possuem custos mais elevados, o que, em muitas situações, implica recursos mais escassos para a educação. Dessa forma, estudantes de famílias menores podem apresentar condições mais facilitadas, em média, quando comparados com alunos de famílias maiores. As estimativas sinalizam para esta conclusão, dado que para todos os quartis, a cada incremento de um membro no grupo familiar, o desempenho médio dos alunos do Estado do Rio Grande do Sul, no Enem, foi menor em aproximadamente $0,70 \%$.

Complementando, para a cor ou etnia do aluno, obteve-se uma relação negativa e significativa para os três quartis analisados. Especificamente quando se analisa os $25 \%$ que obtiveram menores proficiências, obteve-se desempenho inferior de 3,26\% para aqueles alunos de cor negra. Já ao analisar o quartil das maiores proficiências $(0,75)$, o aluno de cor negra obteve desempenho, em média, de 4,0\% inferior aos demais.

Estes resultados demonstram que, independentemente do quartil analisado, o desempenho de alunos negros foi inferior aos demais, o que pode estar associado às condições socioeconômicas, conforme relatado por Alves e Soares (2002). Também retrata a estreita relação existente entre a desigualdade social e a desigualdade educacional que repercute na ausência de igualdade de oportunidades educacionais (ZACCHI, 2016), assim como explica grande parte da desigualdade de renda (FERREIRA; VELOSO, 2006).

Informações complementares sobre as estimativas, como alterações nos coeficientes da regressão em cada quartil, podem ser visualizadas na Figura A.1, do Apêndice. Esta análise é importante quando se objetiva realizar comparações entre os diferentes quartis. A dinâmica mostra que as retas se ajustam de formas diferentes entre os quartis, indicando que as disparidades entre as médias são maiores para os alunos com melhor desempenho no Enem. De outra forma, para os alunos com menores proficiências, o ambiente socioeconômico e familiar tende a influenciar menos quando comparados com os alunos de melhores desempenhos. 
Somente esta análise, entretanto, não é suficiente para concluir que há diferença entre os coeficientes dos diferentes quartis. Neste sentido, foi realizado o teste de Wald para diferenças nos coeficientes entre os quartis $(0,25),(0,50)$ e $(0,75)$, respectivamente. $O$ resultado do teste tem estatística $F$ no valor 5407,56 , indicando a rejeição da hipótese nula de igualdade dos coeficientes, confirmando que há diferença estatística entre os quartis analisados e que o desempenho escolar relaciona-se de forma distinta com as variáveis referidas.

\section{Resultado do Turnaround Point}

Complementando, apresenta-se o Turnaround point, que permite analisar como a idade afetou dinamicamente o desempenho dos alunos do Rio Grande do Sul no Enem, no ano de 2017. Os resultados, considerando os quartis examinados, encontram-se na Tabela 3.

Tabela 3 - Resultado do Turnaround point

\begin{tabular}{cccc}
\hline Turnaround point & QREG (0.25) & QREG (0.50) & QREG (0.75) \\
\cline { 2 - 4 } & $15.9^{* * *}$ & $18.8^{* * *}$ & $20.3^{* * *}$ \\
\hline
\end{tabular}

$* * *, * *$ e $*$ indica que a hipótese nula é rejeitada ao nível de significância de $1 \%, 5 \%$ e $10 \%$ respectivamente.

Fonte: Elaborada pelos autores com base nos resultados da pesquisa (2019).

Quando se observa a relação da idade com o desempenho educacional verifica-se que as maiores proficiências estão associadas às maiores idades médias. Os resultados demonstram que, no quartil 0,25 , a idade que maximiza a melhor proficiência está em torno de 15,9 anos. Para o quartil 0,5, ou a mediana, a idade que maximiza melhor proficiência aproxima-se de 19 anos (18,8 anos), enquanto que para o quartil 0,75 a idade que maximiza a melhor proficiência ficou em 20,3 anos.

Este resultado, a priori, demonstra a diversificação do perfil etário dos participantes do Enem e a tendência para a sua apropriação como instrumento de acesso ao Ensino Superior. Ao analisar-se o menor Turnaround point, do primeiro quartil, pode-se sugerir que a idade reduzida indica a condição de que alguns alunos prestam o exame, embora não tenham concluído o Ensino Médio, com o objetivo de praticar e adquirir experiência, uma vez que o Enem não impõe restrição de idade aos candidatos.

Também pode ser reflexo da diminuição progressiva da distorção idade-série no Ensino Médio que vem causando uma juvenilização do público desse nível (CORTI, 2013). A despeito destes aspectos, o aluno que começou a praticar o exame em idade tenra, quando realiza a prova com mais idade e com mais conhecimento/experiência tende a obter melhor desempenho para ingressar no Ensino Superior.

Por outro lado, o maior Turnaround point, do último quartil, de aproximadamente 20 anos, indica a condição daqueles alunos que podem estar buscando uma segunda Graduação ou procurando trocar de curso, como também por aqueles alunos que buscam ingressar em cursos e universidades mais disputadas, realizando repetidas vezes o exame. Ainda demonstra que ao mesmo tempo, o Enem tem passado por um processo de reestruturação do perfil etário, pelo aumento da participação dos alunos de maior idade. 


\section{CONCLUSÕES}

O desempenho escolar é, de forma recorrente, tema central de vastas discussões que envolvem desigualdades social e econômica, tendo como preâmbulo quais fatores influenciam neste processo. Com base neste aspecto, buscou-se compreender as diferenças entre os ensinos público e privado no Estado do Rio Grande do Sul, a partir de dados referentes ao desempenho dos alunos no Exame Nacional do Ensino Médio (Enem), no ano de 2017, utilizando-se da modelagem de regressão quantílica.

Essa modelagem empregada possibilitou obter os determinantes do desempenho educacional dos alunos, considerando os quartis das maiores e menores proficiências. Os resultados confirmaram as relações evidenciadas pela literatura quanto ao desempenho inferior da escola de natureza pública comparado ao da escola de natureza privada, destacando-se que nos quartis analisados a maior diferença encontrou-se para o quartil das melhores proficiências. Este desempenho inferior está associado também à idade do aluno, uma vez que se encontrou que o resultado das proficiências mais altas estão relacionadas à idade mais elevada, enquanto o desempenho das proficiências mais baixas está relacionado com idade menor, refletindo, assim, condições de aprendizado e experiência na prestação do exame.

As relações socioeconômicas familiares mostraram outra dimensão relevante para a explicação do desempenho escolar. As variáveis renda, acesso à Internet e mãe com formação superior estão associadas com as maiores proficiências no Enem, reforçando o argumento de que as desigualdades sociais e econômicas estão na base das desigualdades educacionais. Este resultado justifica a necessidade de políticas públicas educacionais que minimizem o efeito "dotação inicial", buscando a igualdade de oportunidades no acesso ao Ensino Superior como forma de minimizar as crescentes desigualdades educacionais.

Embora o estudo tenha mostrado coerência com as proposições teóricas e metodológicas esperadas, a análise limita-se ao espaço de tempo e região definidos, conquanto comparações se tornam possíveis, a generalização dos resultados é limitada. Também deve-se destacar que a base informacional do Enem não possibilita discutir qualidade dos sistemas educacionais, uma vez que não é uma base nem censitária nem amostral, caso da Prova Brasil ou do Pisa. Assim sendo, futuros trabalhos sobre esta temática poderão expandir a análise incorporando outras bases informacionais e/ou outras modelagens como forma de fornecer evidências robustas que auxiliem a tomada de decisão aos policy makers.

\section{REFERÊNCIAS}

ALBERNAZ, Â.; FERREIRA, F., H., G.; FRANCO, C. Qualidade e equidade na educação fundamental brasileira. Pesquisa e Planejamento Econômico, v. 32, n. 3, p. 453-476, 2002.

ALVES, M. T. G.; SOARES, J. F. Cor do aluno e desempenho escolar: as evidências do Sistema de Avaliação do Ensino Básico - SAEB. In: ENCONTRO ANUAL DA ANPOCS, 26., 2002, Caxambu: [s.n.], 2002.

BARBETTA, P. A.; ANDRADE, D. F. D.; TAVARES, H. R. Estudo de fatores associados através de regressão quantílica hierárquica. Estudos em avaliação educacional, São Paulo, v. 29, p. 320-349, maio/ago. 2018.

BLACK, S. E.; DEVEREUX, P. J. Recent Developments in Intergenerational Mobility. NBER Working Paper, Amsterdam, v. 4, abr. 2011.

CAMERON, A. C.; TRIVEDI, P. K. Microeconometrics Using Stata. Lakeway Drive: Stata Corp LP, 2009. 
CONFEDERAÇÃO NACIONAL DOS MUNICÍPIOS (CNM). Análise sobre os indicadores educacionais do Rio Grande do Sul. Estudos Técnicos CNM, v. 2, p. 41-47, abr. 2009.

CORTI, A. P. As diversas faces do Enem: análise do perfil dos participantes (1999-2007). Estudos em Avaliação Educacional, São Paulo, v. 24, n. 55, p. 198-221, abr./ago. 2013.

COSTA-BEBER, L. B. et al. Processos seletivos de Universidades Públicas da Região Sul do Brasil: movimento de mudanças a partir do Novo Enem. Revista Brasileira de Pesquisa em Educação em Ciências, v. 14, p. 217-232, 2014.

DIAS, R. E. Profissionalização docente e a cultura da performatividade. In: ENDIPE - ENCONTRO NACIONAL DE DIDÁTICA E PRÁTICA DE ENSINO, 13., 2006, Recife. Anais [...]. Recife, 2006.

FERREIRA, S. G.; VELOSO, F. A reforma da educação. In: PINHEIRO, A. C.; GIAMBIAGI, F. Rompendo o marasmo: a retomada do desenvolvimento no Brasil. Rio de Janeiro: Elsevier, 2006.

FOLHA DE SÃO PAULO. Veja o desempenho da sua escola no Enem 2018. Confira a posição de sua escola no ranking nacional do Enem de 2016, 2017. Disponível em: https://www1.folha.uol.com.br/educacao/2017/12/1942488-confira-a-posicao-de-sua-escola-no-ranking-nacional-do-enem-de-2016.shtml. Acesso em: 16 nov. 2019.

FRANCO, A. M. P.; MENEZES F. N. Uma análise de rankings de escolas brasileiras com dados do SAEB. Estudos Econômicos, São Paulo, v. 42, n. 2, p. 263-283, abr./jun. 2012.

GREENE, W. H. Econometric analysis. 5. ed. New York: Pearson Education, 2003.

INEP. Instituto Nacional de Estudos e Pesquisas Educacionais Anísio Teixeira. Primeiro dia do Enem 2017 termina com baixo índice de candidatos eliminados. INEP, 2017. Disponivel em: http://portal.inep.gov.br/ artigo//asset_publisher/B4AQV9zFY7Bv/cntent/primeiro-dia-do-enem-2017-termina-com-baixo-indicede-candidatos eliminados/21206. Acesso em: 28 jun. 2019.

INEP. Instituto Nacional de Estudos e Pesquisas Educacionais Anísio Teixeira. Exame Nacional do Ensino Médio (Enem). 2019. Disponível em: http://portal.inep.gov.br/web/guest/educacao-basica. Acesso em: 20 set. 2019.

KOENKER, R.; BASSETT, G. Regression Quantiles. Econometrica, v. 46, n. 1, p. 33, 1978.

MACHADO, A. F. et al. Qualidade do ensino em matemática: determinantes do desempenho de alunos em escolas públicas estaduais mineiras. Economia, v. 9, n. 1, p. 23-45, 2008.

MADEIRA, F, R. Educação e desigualdade no tempo de juventude. In: CAMARANO, Ana Amélia (org.). Transição para a vida adulta ou vida adulta em transição. Brasília: Instituto de Pesquisa Econômica Aplicada (Ipea). 2006. p. 139-170.

MEDEIROS, M.; OLIVEIRA, L. F. B. D. Desigualdades regionais em educação:potencial de convergência. Revista Sociedade e Estado, v. 29, p. 561-586, maio/ago. 2014.

MORAES, A. G. E. D.; BELLUZZO, W. O diferencial de desempenho escolar entre os sistemas de ensino. Nova Economia, Belo Horizonte, v. 24, n. 2, p. 409-430, ago. 2014.

NOGUEIRA, L. C. B.; DE ALENCAR, E. F.. Tal pai, tal filho? Uma análise dos efeitos fatores de circunstâncias sobre o desempenho dos alunos na avaliação do Pisa 2012. Pesquisa e Planejamento Econômico, v. 49, n. $1,2019$.

RIGOTTI, J. I. R. A transição da escolaridade no Brasil e as desigualdades regionais. Revista Brasileira de Estudos de População, v. 18, p. 59-73, jan./dez. 2001.

SILVA, E. N. D.; JÚNIOR, S. D. S. P. Sistema financeiro e crescimento econômico: uma aplicação de regressão. Aplicada, Ribeirão Preto, v. 10, jul./set 2006.

SILVA, L, A.; MORINO, A, H; SATO, T. M. C. Prática de mineração de dados no Exame Nacional do Ensino Médio. In: WORKSHOPS DO CONGRESSO BRASILEIRO DE INFORMÁTICA NA EDUCAÇÃO, v. 3, n. 1, p. 651660, 2014, Dourados, MS. Anais [...]. Dourados, MS: Sociedade Brasileira de Computação, 2014. Disponível em: http://www.br-ie.org/pub/index.php/wcbie/article/view/3289. Acesso em: 22 abr. 2017.

SOARES, J. F.; COLLARES, A. C. M. Recursos familiares e o desempenho cognitivo dos alunos do ensino básico brasileiro. Dados: Revista de Ciências Sociais, Rio de Janeiro, v. 49, n. 3, p. 615-650, 2006.

TELES, T. R. Política de cotas do ensino superior brasileiro: uma análise percuciente in faciem do princípio constitucional da igualdade. Ius Gentium, Curitiba, PR, v. 12, n. 6, 2015. ISSN 2237-4965.

TRAVITZKI, R. ENEM: limites e possibilidades do Exame Nacional do Ensino Médio enquanto indicador de qualidade escolar. 2013. 320 p. Tese (Doutorado - Programa de Pós-Graduação em Educação. Área de Concentração: Educação e Filosofia) - Universidade de São Paulo, Faculdade de Educação, São Paulo, 2013.

ZACCHI, R. C. Desempenho escolar e desigualdades educacionais no Brasil: uma análise a partir do Exame Nacional do Ensino Médio (ENEM). 288 f. 2016. Tese (Doutorado em Sociologia Política) - Universidade Estadual do Norte Fluminense Darcy Ribeiro, Campos dos Goytacazes, Rio de Janeiro, 2016. 


\section{ANEXO A}

Figura A.1 - Resultados em termos de quartis
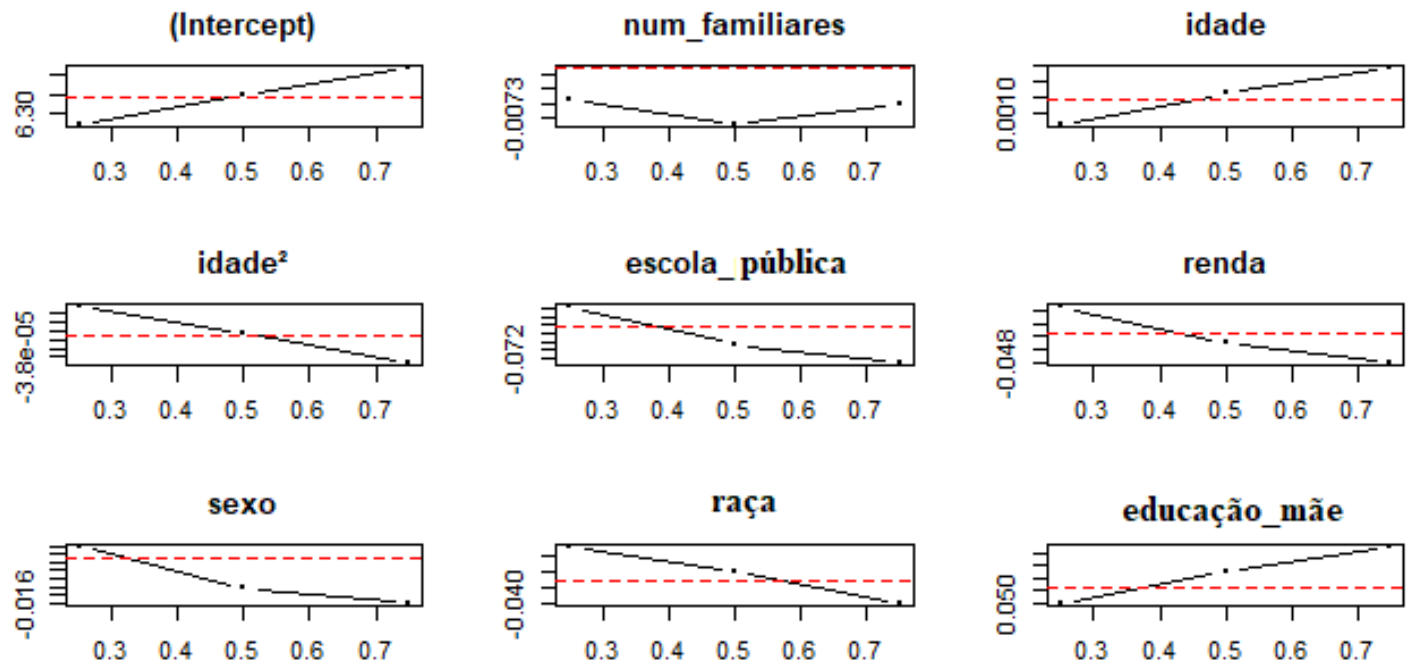

internet

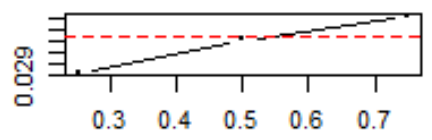

Fonte: Elaborada pelos autores com base nos resultados da pesquisa (2019).

Tabela A.1 - Resultado do teste de Wald

\begin{tabular}{lll}
\hline Teste & Estatística $t$ & Prob. \\
\hline Wald & $5407,56 * * *$ & 0,0000 \\
\hline
\end{tabular}

$* * *, * *$ e $*$ indica que a hipótese nula é rejeitada ao nível de significância de $1 \%, 5 \%$ e $10 \%$ respectivamente.

Fonte: Elaborada pelos autores com base nos resultados da pesquisa (2019). 